\title{
EFFICACY OF LEVAMISOLE AS A SINGLE AGENT IN MAINTAINING REMISSION IN STEROID DEPENDANT NEPHROTIC SYNDROME
}

Kudagammana $\mathrm{ST}^{1}$, Thalgahagoda $\mathrm{S}^{1}$, Abeyagunawardena $\mathrm{S}^{2,3}$, Karunadasa $\mathrm{UI}^{4}$, Abeyagunawardena $\mathrm{AS}^{4}$

${ }^{1}$ Teaching Hospital, Peradeniya,

${ }^{2}$ Teaching Hospital, Kandy,

${ }^{3}$ Teaching Hospital, Gampola,

${ }^{4}$ Department of Paediatrics, Faculty of Medicine, University of Peradeniya

Corresponding author:ProfA.S.Abeygunawardana E-mail: asiriabey26@gmail.com

\begin{abstract}
Introduction

Levamisole (LEV) is an anti-helminthic drug which subsequently has shown immunomodulatory properties. It has been used successfully in conjunction with low-dose alternate-day prednisolone in steroid dependant nephrotic syndrome (SDNS). This randomised controlled study was carried out between years 2002 and 2005 at a single centre in Sri Lanka to evaluate the efficacy of LEV as a single agent following a prolonged period of combination therapy of LEV and prednisolone.
\end{abstract}

\section{Method}

Sequential Children with SDNS in stable remission who had been treated with LEV and low dose alternate-day prednisolone $(0.1-0.6 \mathrm{mg} / \mathrm{kg})$ for 2 years were recruited and randomised into one of two groups. The test group received LEV $(2.5 \mathrm{mg} / \mathrm{kg})$ on alternate-days for one year and the control group received no treatment. Urine protein excretion was performed and recorded by parents on daily basis and the finding of $3+$ or more proteinuria for three consecutive days was diagnostic of relapse.

\section{Results}

There were 42 in the test group (median age 8.4 years) and 34 in the control group (median age 7.2 years). During one year of follow up, 26/34 in the control group and 8/42 in the test group suffered a relapse. ( $p<0.001$ comparison of 2 proportions using Standard Error. CI- 0.105 to $0.49)$. No adverse effects of LEV were encountered.

\section{Conclusion}

Levamisole is safe, affordable and effective as a single agent in maintaining remission in SDNS.

Keywords - Levamisole, single agent, long-term therapy, steroid-dependent nephrotic syndrome

\section{Introduction}

Nephrotic syndrome(NS) is a chronic distressing disorder with an annual incidence of 2-4 per 100,000 Caucasian children in the United Kingdom. A reported incidence of 9-16 per 100,000 among British Asian children hints at a racial variation in susceptibility. Even though such figures are not available for native Asians, unpublished data suggest a similar incidence ${ }^{1}$.

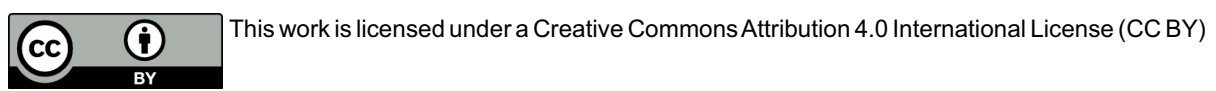


Children with steroid-sensitive nephrotic syndrome have a good long-term prognosis. However around $80 \%$ of these patients experience relapses after 8 weeks of oral corticosteroid therapy, resulting in further course of steroids. Half of these children would have steroid-dependent nephrotic syndrome (SDNS) while $36-50 \%$ of the children who do not respond to steroid therapy eventually progress to end-stage renal failure in 10 years ${ }^{2,3}$. Prolonged or repeated use of corticosteroids often results in serious side effects, such as hypertension, growth failure and cushingoid features. Different immunosuppressive drugs such as cyclophosphamide, levamisole (LEV) and cyclosporine have been used in children with frequently-relapsing NS (FRNS), in order to minimize side effects of steroid toxicity ${ }^{4}$.

In the late sixties cyclophosphamide was reported as an effective agent in maintaining sustained remission in $\mathrm{SDNS}^{5}$. Nonetheless, side-effect profile of cyclophosphamide has been a cause for concern. Bone marrow suppression with neutropenia, lymphopenia and thrombocytopenia, alopecia, nausea, abdominal pain and discomfort and haemorrhagic cystitis constitute the shortterm side effects of cyclophosphamide while long-term side effects include increased risk of future malignancy and potential gonadal toxicity ${ }^{6}$. In the mid 1980's immunomodulatory drug LEV and calcineurin inhibitor cyclosporine A were added to the armamentarium of therapies with variable success rate and side effects. While the incidence of reported side effects with LEV is low, the side effects profile of cyclosporine is substantial including arterial hypertension, hypertrichosis, gingival hyperplasia, hypomagnesaemia, hyperuricaemia and potential nephrotoxicity where the histological changes may be indistinguishable from focal segmental glomerulosclerosis $^{7,8,9}$.
Levamisole (LEV) is an anti helminthic drug with immunomodulatory properties which has been successfully used at a dosage of $2.5 \mathrm{mg} / \mathrm{kg} /$ alternate-day in conjunction with alternate-day prednisolone for FRNS and SDNS. The major advantage of LEV is its steroid sparing-effect which comes with minimal side effects. There is accumulating evidence to suggest that LEV is an attractive alternative which could contribute towards a reduction of maintenance dose of corticosteroids and a prolonged remission period ${ }^{10,11,12,13,14}$. Among the different drugs used as steroid sparing agents in steroidsensitive nephrotic syndrome (SSNS) with frequent relapses and steroid dependency, LEV is the least toxic and the least expensive $^{13,14,15}$.

In the Asian subcontinent LEV has been used widely for SDNS with variable success rates. Evidence on the efficacy of LEV is limited to a few clinical trials that are confounded by methodological limitations. Statistical analysis of these trials showed that LEV reduces the risk of a relapse during treatment ${ }^{16,17}$. From the available information, it is difficult to derive conclusions on the steroid-sparing effect, the long-term efficacy, and safety, as well as possible differences in efficacy in different subgroups of SSNS patients.

This randomized, controlled study was designed to evaluate the efficacy and safety of LEV therapy as a single agent in maintaining remission in patients with SDNS.

\section{PATIENTS AND METHODS}

\section{Study population}

Children with steroid dependent nephrotic syndrome attending the renal clinic at a tertiary referral centre in Sri Lanka were considered for recruitment. Following inclusion and exclusion criteria were used for selection of patients. 


\section{Inclusion criteria}

1. Children who had been treated with maintenance low dose $(0.1-0.6 \mathrm{mg} / \mathrm{kg})$ alternate-day oral prednisolone and alternate-day $\operatorname{LEV~}(2.5 \mathrm{mg} / \mathrm{kg})$ for 2 years.

2. Relapse free during the preceding 6 months

3. Age between 3-14 years

\section{Exclusion criteria}

1. Children who have previously received immunosuppressive therapy other than prednisolone and LEV

2. Children with renal histology other than minimal change disease

\section{Method}

Sequential children who satisfied the entry criteria were randomised in to 2 groups by using envelope method. All medications had been stopped in the control group while in the test group LEV was continued as a single agent on alternate-day basis $(2.5 \mathrm{mg} / \mathrm{kg})$ for a period of one year. All patients were reviewed monthly focusing on recurrence of proteinuria and potential side effects of LEV therapy. Full blood count, serum creatinine and liver function tests were performed every 3 months in both groups and parents of all patients were asked to check and record the daily urinary protein excretion. Parents were asked to report immediately if there was ++ or more proteinuria for 3 consecutive days. Urinary protein excretion +++ or more for 3 consecutive days was considered as a relapse. Prior to the study, informed written consent was obtained from the parents as well as the child where appropriate. Ethical clearance for the study was obtained in 2001.

\section{Results}

Between years 2002 to 2005 , seventy-six (76) patients were enrolled for the study. There were 42 patients in the test group (median age 8.4 years, range $3.5-14.6$ years) and 34 in the control group (median age 7.2 years, range $2.8-13.8$ years). Sex ratio was similar in both groups (male: female- 1.6:1). During one year of follow up, 26/34 (76\%) in the control group and $8 / 42(19 \%)$ in the test group suffered a relapse $(\mathrm{p}<0.001$ comparison of 2 proportions using Standard Error. CI 0.105 to 0.49 ) (Figure 1). None of the patients suffered from LEV induced adverse effects such as neutropenia, leukopenia, vasculitic skin rashes and liver dysfunction.

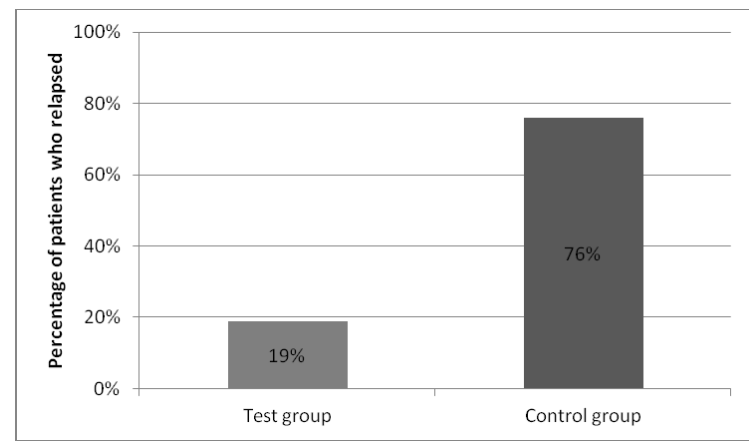

Figure - Patients in the test and control groups who relapsed during the one year follow-up

\section{Discussion}

The importance of immune system in the pathogenesis of childhood NS was first suggested in $1974{ }^{16}$. Subsequent reports have attributed the observed suppression of immune responsiveness in the disease to the dysregulation of T-lymphocyte, thereby implicating a major role of T-lymphocytes in its pathogenesis ${ }^{17,18}$. Though the exact action of cytokines on the glomerular epithelium is not yet elucidated, humoral and cellular immune mechanisms mediated by cytokines are thought involve in the generation of NS, especially in the minimal-change histology. One of the main observations is the reduced interleukin-2 (IL-2) production ${ }^{19,20}$. Some studies have suggested that minimal change nephrotic syndrome (MCNS) is a T helper 2dominated (Th2) disease, having observed higher levels of serum interleukin-13 (IL-13) in patients with $\mathrm{MCNS}^{21,22}$. These observations represent the scientific rationale for the use of immunosuppressive drugs in childhood NS. Children with frequently relapsing or steroid dependent disease are the main candidates for such cytotoxic or other immunosuppressive treatment, owing to the significant steroid toxicity resulting from multiple courses of high-dose corticosteroids. 
Several studies suggested LEV as the first choice of non-steroidal immunosuppressive agent to achieve less frequent relapses and longer sustained remission in children with FRNS or SDNS, in addition to the decrease of steroid-related side effects ${ }^{23,24}$. Significant reduction of both relapse rate and cumulative steroid dose by LEV in SDNS and FRNS patients was reported in the studies of Sumegi, Madani and Al-Saran ${ }^{25,10,11}$. In a later study by Boyer et al LEV had the additional benefits of normalized blood pressure in hypertensive patients and improved height velocity, even after cessation of LEV therapy $^{12}$. In the retrospective analysis of Abeyagunawardena et al, LEV effectively induced remission in $30 \%$ of children when prescribed as the first steroid-sparing agent and $66 \%$ for post-cyclophosphamide steroid dependency $^{26}$. However, such an effect was not sustained for a long period in some other studies $^{27,28}$. In 1997 Bagga et al observed an 8-12 months duration of sustained remission $^{30}$ while this period was only 3 months in the study of the British Association for Paediatric Nephrology back in $1991^{31}$.

No literature-based firm recommendations can be made on how prednisolone should be withdrawn during LEV therapy in order to minimise the risk of relapse. In the present study, levamisole was used as a single agent following a prolonged period of combination therapy of LEV and prednisolone in SDNS patients. We were able to observe significantly lesser relapse rates with LEV therapy than most of the earlier studies which assessed the effect of LEV while on tapering or no steroids ${ }^{29,31}$. A study by Fu et al demonstrated that a twoyears prolonged therapy with LEV significantly reduced the frequency of relapses from 5.74 to 1.91 and oral prednisolone dose from 0.62 to 0.21 $\mathrm{mg} / \mathrm{kg} /$ day at the 2 -year follow up period ${ }^{14}$.

The major advantage of LEV is its steroidsparing effect with minimal toxicity, although vasculitic rash, liver toxicity and reversible leukopenia have been infrequently reported ${ }^{32,33}$. In our study, there were no such effects of LEV encountered.
The options for treatment of patients with SDNS are limited. Prolonged administration of large doses of corticosteroids would be hazardous whereas second course of cyclophosphamide or long-term use of cyclosporine carries the risk of toxicity. Furthermore, cyclosporine and rituximab are expensive drugs. Therefore, leavamisole appears to be an effective and cheap alternative drug with minimum side effects to treat patients with SDNS, especially in Asian settings.

In conclusion, this study suggests that LEV is a safe and effective drug and can be used as a single agent to induce sustained remission in children with SDNS and hence remains an attractive alternative to corticosteroids. However, further studies are needed to assess the long-term effects of LEV as a single therapeutic agent.

\section{References}

1. Consensus statement on management and audit potential for steroid responsive nephrotic syndrome. Report of a workshop by the British Association for Paediatric Nephrology and Research Unit, Royal College of Physicians. Archives of Disease in Childhood. 1994;70:151-157

2. Sinha M, MacLeod R, Rigby E, Clark A. Treatment of severe steroiddependent nephrotic syndrome (SDNS) in children with tacrolimus. Nephrology Dialysis Transplantation. 2006;21:1848-1854.

Doi:10.1093/ndt/gfi274

3. Mekahli D, Liutkus A, Ranchin B, Yu A, Bessenay L, Girardin E et al. Longterm outcome of idiopathic steroidresistant nephrotic syndrome: a multicenter study. Pediatric Nephrology. 2009;24:1525-1532. Doi:10.1007/s00467-009-1138-5 
4. Durkan AM, Hodson EM, Willis NS, Craig JC. Immunosuppressive agent in childhood nephrotic syndrome: a meta-analysis of randomized controlled trials. Kidney International. 2001;59:1919-27. Doi:10.1046/j.15231755.2001.0590051919.x

5. Trompeter RS. Minimal change nephrotic syndrome and cyclophosphamide. Archives of Disease in Childhood. 1986;61: 727-9.

6. Yap H, Cheung W, Murugasu M, Sim S, Seah C Jordon SC. Th1 and Th2 Cytokine mRNA Profiles in Childhood Nephrotic Syndrome: Evidence for Increased IL-13 mRNA Expression in Relapse. Journal of the American Society of Nephrology.1999;10: 529537

7. Brodehl J. Conventional therapy for idiopathic nephrotic syndrome in children. Clinical Nephrology. 1991;35: S8-15

8. Latta K, von Schnakenburg C, Ehrich JH. A meta-analysis of cytotoxic treatment for frequently relapsing nephrotic syndrome in children. Pediatric Nephrology. 2001;16:271-82

9. Walker RJ, Tiller DJ, Horvath JS, Duggin GG. Malignant lymphoma in a renal transplant patient on cyclosporinA therapy. Australian and New Zealand journal of medicine. 1989;19:154-5. Doi:10.1111/j.14455994. 1989. tb00231.x

10. Madani A, Isfahani ST, Rahimzadeh N, Fereshtehnejad SM, Hoseini R, Moghtaderi M, Mohseni P, Ataiee N. Effect of Levamisole in steroiddependent nephrotic syndrome. Iranian Journal of Kidney Diseases. 2010;4:292-96.
11. Al-Saran K, Mirza K, Al-Ghanam G, Abdelkarim M. Experience with levamisole in frequently relapsing, steroid-dependent nephrotic syndrome.Pediatric Nephrology. 2006;21:201-5. Doi:10.1007/s00467005-2080-9

12. Boyer O, Moulder J, Grandin L, Somers M. Short- and long-term efficacy of levamisole as adjunctive therapy in childhood nephrotic syndrome. Pediatric Nephrology. 2008;23:575-580.

Doi:10.1007/s00467-007-0708-7.

13. Trompeter R, Hicks J, Lloyd B, White $\mathrm{R}$, Cameron J. Long-Term outcome for Children with Minimal-Change Nephrotic Syndrome. The Lancet. 1985;325:368-370. Doi:10.1016/S0140-6736(85)91387-X

14. Fu LS,.Chi CS. Levamisole in steroidsensitive nephrotic syndrome children with steroid-dependency and/or frequent relapses. ActaPaediatrica Taiwanica. 2000;41:80-4.

15. British Association for Paediatric Nephrology. Levamisole for corticosteroid-dependent nephrotic syndrome in childhood. The Lancet. 1991;337:1555-7. Doi:10.1016/01406736(91)93257-A

16. TrompeterRS, Layward L, Hayward AR. Primary and secondary abnormalities of $\mathrm{T}$ cell sub populations. Clinical \& Experimental Immunology. 1978;34:388-92.

17. Shalhoub RJ. Pathogenesis of lipoid nephrosis: a disorder of T-cell function. The Lancet. 1974;304:556-560. Doi:10.1016/S0140-6736(74)91880-7 
18. Bouissou F, Meissner I, Konrad M, Sommer E, Mytilineos J, Ohayon E, Sierp G, Barthe B, Opelz G, CambonThomsen A, et al. Clinical implications from studies of HLA antigens in idiopathic nephrotic syndrome in children. Clinical Nephrology. 1995;44:279-83

19. Hulton SA, Shah V, Byrne MR, Morgan G, Barratt TM, Dillon MJ. Lymphocyte subpopulations, interleukin-2 and interleukin-2 receptor expression in childhood nephrotic syndrome. Pediatric Nephrology.1994;8:135-139. Doi:10.1007/BF00865458

20. Topaloglu R, Saatci U, Arikan M, Canpinar H, Bakkaloglu A, Kansu E (1994). T-cell subsets, interleukin-2 receptor expression and production of interleukin-2 in minimal change nephrotic syndrome. Pediatric Nephrology. 1994;8:649-52. Doi:10.1007/BF00869075

21. Cheung W, Wei CL, Seah CC, Jordan SC, Yap HK. Atopy, serum IgE, and interleukin-13 in steroid-responsive nephrotic syndrome. Pediatric Nephrology.2004;19:627-632. Doi:10.1007/s00467-004-1438-8

22. Yap HK, Cheung W, Murugasu B, Sim SK, Seah CC, Jordan SC. Th1 and Th2 cytokine mRNA profiles in childhood nephrotic syndrome: evidence for increased IL-13 mRNA expression in relapse. Journal of the American Society of Nephrology.1999;10:529537.

23. Mehta KP, Ali U, Kutty M, Kolhatkar. Immunoregulatory treatment for minimal change nephrotic syndrome. Archives of Disease in Childhood. 1986;61:153-8.

Doi:10.1136/adc.61.2.153
24. La Manna A, Politoc C, Del Gado R, Foglia AC. Levamisole in children's idiopathic nephrotic syndrome.Child Nephrology and Urology. 198889;9:200-2.

25. Sumegi V, Haszon I, Ivanyi B, Bereczki C, Papp F, TuriS. Long-term effects of levamisole treatment in childhoodnephrotic syndrome. Pediatric Nephrology. 2004;19:135460. Doi:10.1007/s00467-004-1608-8

26. Abeyagunawardena AS, Dillon MJ, Rees L, van'tHoffW, Trompeter RS. The use of steroid-sparing agents insteroid-sensitive nephrotic syndrome. Pediatric Nephrology.2003;18:919-24. Doi:10.1007/s00467-003-1216-z

27. Tanphaichitr P, Tanphaichitr D, Sureeratanan D, Chatasing S. Treatment of nephrotic syndrome with levamisole. Journal of Pediatrics.1996;96:490-3. Doi:10.1016/S0022-3476(80)80707-4

28. Ksiazek J, Krynski J. Evaluation of the efficacy of levamisole in corticosteroid $\neg$ dependantnephrotic syndrome in children. PediatriaPolska. 1995;70: 1037-42.

29. Kemper MJ, Amon O, Timmermann-K, Altrogge H, Muller-Wiefel DE. The treat $\neg$ ment with levamisole of frequently recurring steroid-sensitive idiopathic nephrotic syndrome in children.Deutsche medizinischeWochenschrift. 1998; 123:239-43.

30. Bagga A, Sharma A, Srivastiva RN. Levamisole therapy in corticosteroid $\neg$ dependentnephrotic syndrome. Pediatric Nephrology. 1997;11:415-7. Doi:10.1007/s004670050307 
31. British Association for Pediatric Nephrology. Levamisole for corticosteroid-dependent nephrotic syndrome in childhood. The Lancet. 1991;337:1555-7. Doi:10.1016/01406736(91)93257-A

32. Bagga A, HariP. Levamisole-induced vasculitis. Pediatric Nephrology. 2000;14:1057-8.
33. Bulugahapitiya DT. Liver toxicity in a nephrotic patient treated with levamisole. Archives of Disease in Childhood.1997;76:289.

Doi:10.1136/adc.76.3.289 